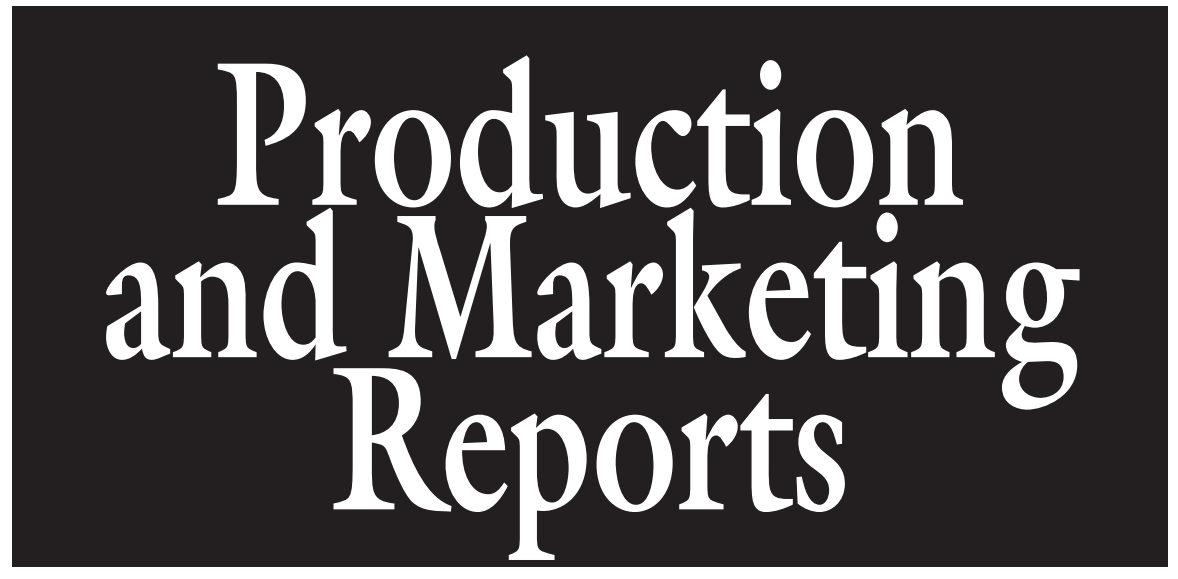

\section{Costs of Food Safety Certification on Fresh Produce Farms in Vermont}

\author{
Florence A. Becot ${ }^{1,3}$, Virginia Nickerson ${ }^{2}$, David S. Conner ${ }^{1}$, \\ and Jane M. Kolodinsky ${ }^{1}$
}

\begin{abstract}
AdDitional INDEX wORDs. good agricultural practices, GAPs, microbial contamination, foodborne illnesses

SUMMARY. This article addresses the economic costs of good agricultural practices (GAPs) audits of small and medium size farms in Vermont. It focuses on the costs of infrastructure, equipment, and labor required to successfully pass a U.S. De-

partment of Agriculture (USDA) GAPs audit. In-depth interviews and surveys of produce farmers in 2011 revealed that the cost of GAPs certification ranges between $\$ 37$ and \$54 per acre, and an additional 7 hours were required each week during the growing season. Based on this exploratory research, certifying all the farms in Vermont would cost between $\$ 228,216$ and $\$ 3,019,114$. Our study explored all the criteria of the certification and measured the costs of GAPs from planning stages to daily record keeping more than one year after the certification was achieved. This study provides information to farmers who are considering GAPs certification. It also provides background information to agricultural service providers and policymakers planning for the future of the fresh produce industry.
\end{abstract}

$\mathrm{T}$ 2020 Healthy People initiative of the U.S. Department of Health and Human Services aims to increase the U.S. consumption of fruit and vegetables by $80 \%$ and $37 \%$ respectively by 2020 , while reducing the number of outbreaks of foodborne illnesses in fruit and vegetables by $10 \%$ (U.S. Department of Health and Human Services, 2010a, 2010b). The Centers for Diseases Control estimate that foodborne

\footnotetext{
We would like to thank the farmers who participated in the research project, University of Vermont Extension for the research grant, and our colleagues at the University of Vermont. We thank Shermain Hardesty, Mary Hendrickson and the anonymous reviewers.

${ }^{1}$ Department of Community Development and Applied Economics, University of Vermont, 146 University Place, Burlington, VT 05405

${ }^{2}$ UVM Center for Sustainable Agriculture, $106 \mathrm{High}$ Point Center, Suite 300, Colchester, VT 05446

${ }^{3}$ Corresponding author. E-mail: fbecot@uvm.edu.
}

infections cause 48 million illnesses (one in six Americans) including 128,000 hospitalization and 3000 deaths each year in the United States (Centers for Disease Control and Prevention, 2011). In the 1970s, fruit and vegetables were responsible for about $1 \%$ of foodborne disease cases, but had increased to $12 \%$ by the 1990s. The fruit and vegetable-related outbreaks have recently outpaced those related poultry, beef, and pork (Bassett and Mcclure, 2008; Smith Dewaal et al., 2012). This increase in outbreaks may be attributed to two factors: increased consumption of fruit and vegetables
(USDA, 2011), and better tracking of outbreaks (Mead et al., 1999). Nevertheless, improving food safety of fresh produce should remain a focus of all actors involved in the production, distribution, and preparation of fresh produce.

GAPs were developed by the USDA to provide guidance on agricultural, handling, and processing steps that can reduce the microbial food safety risks associated with fresh produce (U.S. Department of Health and Human Services, Food and Drug Administration (FDA), and Center for Food Safety and Applied Nutrition, 1998). Although GAPs were developed over 10 years ago, there is limited research on the costs of implementation to farmers. This article addresses the economic costs of GAPs audit on farms in Vermont. Surveys and indepth interviews were used to answer the following research questions: 1) how much does USDA GAPs certification cost farmers?, 2) how much labor is needed for GAPs certification?, and 3) how much would it cost to certify all the farms in Vermont?

\section{Background}

Addressing the issue of produce safety is critical. Recent recalls of cantaloupe (Cucumis melo var. cantalupensis) in Colorado, and strawberries (Fragaria $\times$ ananassa) in Oregon are bringing the question of produce food safety to the forefront for wholesalers, supermarkets, institutional buyers, and customers. Foodborne illness has a significant impact on the U.S. economy and the agricultural and food processing sector. The FDA and Food Safety Inspection Service estimate that $\$ 3$ billion is spent annually on hospitalization, and incidents related to foodborne illnesses cause between $\$ 20$ and $\$ 40$ billion in lost productivity (Almanza and Nesmith, 2004). Produce recalls affect growers through decreases in sales and negative reputational impacts, even when their product was not involved in the recall. (Calvin, 2003; Calvin et al., 2004).

GAPs. GAPs have been developed to provide guidance on agricultural, handling, and processing steps

\begin{tabular}{llll}
\hline $\begin{array}{l}\text { Units } \\
\begin{array}{l}\text { To convert U.S. to SI, } \\
\text { multiply by }\end{array}\end{array}$ & U.S. unit & SI unit & $\begin{array}{l}\text { To convert SI to U.S., } \\
\text { multiply by }\end{array}$ \\
\hline 0.4047 & acre(s) & ha & 2.4711
\end{tabular}


that can reduce the microbial food safety risks associated with fresh produce. Based on the "Guide to Minimize Food Safety Hazards for Fresh Fruits and Vegetables" published by the U.S. Department of Health and Human Services, the FDA, and the Center for Food Safety and Applied Nutrition (1998), the guidelines recommend that proper protocols related to water use, manure management, farmer/worker hygiene, and transportation be based on scientific data regarding risks associated with specific fruit and vegetables (De Roever, 1998). Adherence to GAPs is currently verified through a voluntary audit administered by individual states in partnership with the Agricultural Marketing Service or by private third-party audit agencies. The audit is comprised of seven sections: general questions, farm review (Part 1), field harvesting, and field packing activities (Part 2), house packing facilities (Part 3), storage and transportation (Part 4), wholesale distribution center/terminal warehouse (Part 6), and preventative food defense procedures (Part 7).

Each section is scored on a point system. To become GAPs certified, growers must score at least $80 \%$ on each section. Compliance with the guidelines is verified for individual crops depending on the length of the season: $30 \mathrm{~d}, 31-60 \mathrm{~d}, 61-90 \mathrm{~d}$, and $9 \mathrm{l}+\mathrm{d}$ crops. The audit checklist gives farmers some freedom on how to meet the criteria and allows them to work with the existing farm assets (land and buildings) (Rejesus, 2009).

Currently, the GAPs certification is voluntary; however, some regional chain supermarkets in Vermont, including Hannaford (Scarborough, ME), Price Chopper (Schenectady, $\mathrm{NY}$ ), and wholesale distributors such as Red Tomato (Plainville, MA) and J.P. Sullivan (Ayer, MA), are requiring farmer certification. Tobin et al. (2011) forecasts that the number of supermarkets in Pennsylvania requiring GAPs certification will increase within the next three years. At the time of our study, Hannaford and Price Chopper required farmers to pass the first three sections of the audit for at least one crop. Wal-Mart (Bentonville, $A R$ ) is currently not requiring USDA GAPs, but rather requires the Global Food Safety Initiative.

GAPs certification can offer potential benefits to growers. For example, following GAPs can increase the quality and shelf life of fresh produce by lowering microbial risks (Bihn and Gravani, 2006) and reduces the risk that foodborne disease outbreaks will originate on the farm (Rejesus, 2009). Indirect benefits of GAPs can include improved efficiency and workplace cleanliness and (Calvin et al., 2004; Estrin, 2010). These benefits may accrue as farmers review all of their practices in preparation for the audit, and inform changes that can improve the efficiency, organization, record keeping, and quality control of their operation.

Barriers to seeking produce safety certification include a myriad of food safety standards, cost of new equipment and infrastructure, additional time spent on recordkeeping, and labor capacity (Hardesty and Kusunose, 2009). Unlike organic certification, GAPs certification is done for individual crops and buyers require what crops must be certified. This requirement can be challenging for farmers growing more than a handful of crops as it requires significant time, cost, and effort (Hultberg et al., 2012). Another barrier to GAPs certification is that buyers are not willing to pay more for GAPs certified produce, leaving the financial burden of the certification solely on the farmer who must bear the costs associated with incorporating the new practices (Calvin et al., 2004).

Costs of GAPs. Farmers can benefit from greater knowledge of the cost of GAPs before deciding whether to go through the audit and certification process, yet there is currently limited information on the economic costs of the GAPs certification. Paggi (2008) found it difficult to measure the compliance cost of food safety policies at the farm level because of farm heterogeneity and the unique costs associated with individual operations. Annual labor, audit, and implementation costs have been estimated at $120 \mathrm{~h}$, \$300-\$500 (Hunter et al., 2010) and \$2500-\$3200 (Rejesus, 2009).

Three recent studies have examined the cost of implementing food safety certifications in detail (Estrin, 2010; Hardesty and Kusunose, 2009; Woods and Thornsbury, 2005). Hardesty and Kusunose measured the cost of compliance to the Leafy Green Marketing Agreement (LGMA) for the leafy greens growers of California.
About $99 \%$ of the Californian leafy green growers have joined the LGMA; this industry-wide adoption differentiates it from other food safety programs. Hardesty and Kusunose found that growers with annual revenues greater than $\$ 10$ million benefit from economies of scale and have greater capacities to absorb the costs to comply with LGMA. Total cost of the investments and modifications necessary for LGMA compliance averaged $\$ 21,490$ or $\$ 13 /$ acre and "the sum of the average modifications costs and seasonal food safety costs $\$ 68 /$ acre and represents almost $1 \%(0.93 \%)$ of growers' average lettuce (Lactuca sativa) revenues" (Hardesty and Kusunose, 2009).

Woods and Thornsbury (2005) studied the impact of the adoption of GAPs on strawberry farms using secondary data from state and regional sources. They focused on five GAPs criteria: toilet and hand-washing facilities, hygiene training, packing shed or cooling pad sanitation, irrigation water, and crisis management. The additional costs associated with GAPs for bigger farms were $\$ 66 /$ acre, while the costs for smaller farms were $\$ 288$ /acre.

Estrin (2010) analyzed the case of a Vermont farmer preparing for an initial USDA GAPs certification audit. The farmer grows 40 crops on over 130 acres, employs about 20 people, and his annual gross sales average \$1 million. He started the GAPs certification process by focusing on one crop, kale (Brassica oleracea var. acephala). For the first year, the cost of USDA GAPs certification for the first three sections of the audit was estimated at $\$ 5000$ for capital improvements and labor, $0.5 \%$ of the farm's gross sales. Capital investments projections were between $\$ 6000$ and $\$ 130,000$ depending on the level of compliance. The annual compliance cost would range between $\$ 10,000$ and $\$ 32,000,1 \%$ to $3 \%$ of the farm's total produce sales.

Limited empirical information is available on the cost of GAPs certification on diversified, small- and medium-sized farms, which are common to Vermont and many other states. Hardesty and Kusunose studied the cost of LGMA for leafy green growers in California and the average acreage of the respondents was 2330 , Woods and Thornsbury studied the cost of five GAPs criteria on strawberry growers using secondary data, and 
Estrin studied just one farm getting ready for the certification. Thus, our study contributes to the current literature by measuring the costs of GAPs compliance, as well as labor needs, for a diverse sample of farms; some farms were highly diversified, growing over 40 crops, while other farms grew only a handful of different crops. Through a combination of surveys sent to members of produce grower associations and in-depth interviews with GAPs certified farmers, we measured costs of infrastructure, audit, and labor requirements. Our study explored all the criteria of the certification and measured the cost of implementing GAPs and labor from planning stages to daily record keeping over one year after the certification was achieved. The study was conducted in Vermont, a state that is placing a high emphasis on the consumption of local food and on a strong agricultural sector (Vermont Sustainable Jobs Fund, 2011). Our results can be informative for smaller scale, diversified farms that wish to scale up and sell to buyers requiring GAPs certification to meet the growing demand for locally grown fresh produce.

\section{Methods and materials}

We used multiple methods to research the economic costs of GAPs certification. These included 1) an online survey to measure interest in GAPs audits and the prospective costs of compliance on a larger sample of farms and 2 ) in-depth interviews with 10 farm operators who had achieved USDA GAPs certification to understand the breadth and depth of issues associated with certification. The
University of Vermont's Institutional Review Board approved this protocol (project number CHRBS B11-147).

OnLINe survey. An online survey was used to measure the number of Vermont farms that might be seeking GAPs certification and to get a sense of how much certification would cost these farms. The survey included questions from Hardesty and Kusunose's LGMA study (Hardesty and Kusunose, 2009), as well as questions designed by the principal investigators, with guidance provided by members of Vermont's Produce Safety Working Group. Farmers were asked about the characteristics of their farm including size, number of workers, crops grown, spread of sales and practices, and equipment currently on the farm such as equipment for irrigation, washing and packing of produce. Certified farmers were asked questions about their motivation to seek certification, audit, labor needs, and modification and investments made to pass the certification. Noncertified growers were asked about their intentions around GAPs certification.

The survey sample frame was farmers who belong to a grower association. The link to the online survey was sent to fruit and vegetable growers through the listservs of the Vermont Vegetable and Berry Growers Association [Brattleboro, VT (234)], the Vermont Organic Farmers [Richmond, VT (181)], and the Vermont Tree Fruit Growers Association [Burlington, VT (5l)]. These listservs reached $\approx 366$ growers in Vermont. We calculated an overlap among the listservs of 85 growers and 15 of the e-mail addresses belonged to agricultural service providers implying a sample frame of 366 farmers. The survey opened 15 Mar. and closed 16 May 2011, and listserv members were prompted two times to respond to the survey during this period by representatives of the growers' associations. We received a total of 79 responses, 17 from GAPs certified growers and 62 from nonGAPs certified growers, representing a response rate of $21 \%$. Respondents represent a diversity of Vermont farms along many dimensions (size, geographic location, and crops produced).

Our data analysis consisted of three phases. We began by looking at the characteristics of the farms represented in the survey; descriptive statistics including mean and $\mathrm{CV}$ can be found in Table 1 . The $\mathrm{CV}$ is the ratio of the standard deviation to mean. A coefficient less than one indicates a low variance, while a coefficient greater than one indicates high variance (Giard, 2003). Next, to compare differences across types of producers [certified and not certified, vegetable growers and apple (Malus $\times$ domestica) growers, and farmers growing one crop and farmers growing more than one crop], we compared mean values of number of acres, workers, crops grown, and revenues from various market channels.

Two tests of normality, the Kolmogorov-Smirnov and the ShapiroWilk, were conducted to determine which tests to run to measure differences in responses between groups. These tests showed the data were not normally distributed. The MannWhitney $U$ test was used instead of

Table 1. Descriptive statistics of respondents to a 2011 e-mail survey assessing Vermont vegetable and apple growers' interest in good agricultural practices (GAPs) and the prospective costs of compliance. The total number of farmers who responded to this question was 79 .

\begin{tabular}{|c|c|c|c|c|c|c|}
\hline & \multicolumn{2}{|c|}{ Non-GAPs $(n=62)$} & \multicolumn{2}{|c|}{ GAPs $(n=17)$} & \multicolumn{2}{|c|}{ All $(n=79)$} \\
\hline & Mean & $\begin{array}{c}\text { Coefficient } \\
\text { of variation }\end{array}$ & Mean & $\begin{array}{l}\text { Coefficient } \\
\text { of variation }\end{array}$ & Mean & $\begin{array}{l}\text { Coefficient } \\
\text { of variation }\end{array}$ \\
\hline Year-round workers (no.) & 1 & 0.88 & 7 & 1.44 & 3 & 2.13 \\
\hline Seasonal workers (no.) & 5 & 1.28 & 19 & 0.98 & 8 & 1.48 \\
\hline $\begin{array}{l}\text { Sales to consumers through farmers' market } \\
\text { and on-farm retail }(\%)\end{array}$ & 72 & 0.40 & 15 & 1.16 & 59 & 0.60 \\
\hline Sales to chain supermarkets $(\%)$ & 1 & 4.99 & 40 & 0.80 & 9 & 2.38 \\
\hline Sales to wholesale markets (\%) & 3 & 3.18 & 24 & 1.27 & 7 & 2.46 \\
\hline Sales to other markets $(\%)$ & 5 & 3.49 & 5 & 2.60 & 5 & 3.30 \\
\hline
\end{tabular}

${ }^{\mathrm{z}} 1$ acre $=0.4047$ ha. 
the analysis of variance $\mathrm{F}$ test (Norusis, 2006). Next, we analyzed farmers' readiness and reasons for seeking GAPs certification, and intentions of the non-GAPs certified growers to seek certification. Finally, we measured the cost and labor involved in the GAPs certification process.

IN-DEPTH INTERVIEWS. In-depth interviews were conducted with 10 Vermont farmers who had passed the USDA GAPs audit in 2010. The researchers traveled to each of the 10 farms to conduct the interviews; each interview lasted $\approx \mathrm{l} \mathrm{h}$. The interviews were audiotaped for increased accuracy during the data analysis process. There were two phases to each interview: a semistructured interview and the administration of a cost measurement tool. The cost tool was used to measure the cost of GAPs compliance for each of the 10 farms. This tool was developed using the USDA GAPs and Good Handling Practices Audit Verification Checklist (Estrin, 2010; USDA, 2007a). The cost tool is available upon request.

The farms represented a diversity of produce operations in Vermont and consisted of four mixed vegetable farms, two sweet corn (Zea mays) operations, one greenhouse tomato (Solanum lycopersicum) operation, one potato (Solanum tuberosum) farm, one apple orchard, and one farm that has both an apple orchard and a mixed vegetable enterprise. We used three approaches to analyze the data from the in-depth interviews. First, we looked at the characteristics of the farmers interviewed. Next, we looked at the cost of equipment and infrastructure required to pass the certification audit, followed by an exploration of labor needs.

\section{Results \\ Online survey results}

We aggregated the data into two types of survey respondents: nonGAPs certified growers and GAPs certified growers to calculate descriptive data (Table 1 ).

The farms ranged in size from 0.2 to 350 acres, with an average size of 26 acres. The number of seasonal workers employed by these farms ranged from 0 to 60 workers. On average, the farms that responded to the survey hire eight seasonal workers. In comparison, the average acreage of farms in Vermont is 19 acres (USDA, 2007b). We then looked at how farmers market their produce. The majority of survey respondents' sales are direct to final customers: $59 \%$ of the sales are made through farmers' markets and on-farm retail (farm stand, community-supported agriculture, and/or U-pick); $18 \%$ of the sales are made to schools, hospitals, other institutions, co-op, stores, and/ or restaurants. The rest of the sales are divided between sales to chain supermarkets (10\%), wholesale markets $(8 \%)$, and other $(5 \%)$.

We tested for significant differences in farm size and sales structure between certified and non-certified farms. We used the Mann-Whitney $U$ test, a non-parametric test, since the test of normality revealed that the sample was not normally distributed. The null hypothesis was "the distribution of the variable tested is the same for GAPs certified and non-GAPs certified." We rejected the null hypothesis for acreage, number of seasonal and year-round workers, direct sales to consumers, and sales to supermarket and wholesale $(P \leq 0.01)$. This suggests that for these variables, GAPs certified farms and non-GAPs certified farms have statistically significantly different values. GAPs certified farms tend to be larger than non-certified farms: the average acreage of certified farms is 86 acres and they employ 19 seasonal workers vs. 9 acres and 5 seasonal workers for non-GAPs certified farms. In terms of sales structures, non-GAPs certified farms tend to sell a higher proportion of their production directly to consumers: on average, $72 \%$ of their production is sold through farmers markets and on-farm retail vs. 15\% for certified farmers. The non-GAPs certified farmers sell in smaller quantities to supermarkets $1 \%$ and to wholesale markets $3 \%$ vs. $40 \%$ and $24 \%$ for GAPs certified farms. We failed to reject the null hypothesis for sales made directly to institutions and for other accounts $(P \leq 0.1)$. This means that GAPs certified growers and nonGAPs certified growers are not significantly different when it comes to sales to institutions and other accounts.

Comparison of EQUIPMENT BETWEEN CERTIFIED AND NONCERTIFIED FARMERS. To compare level of readiness for certification between GAPs certified operations and nonGAPs certified operations, we used survey responses about existing equipment and infrastructure as shown in Fig. 1. We asked GAPs certified farmers what modifications and investments they made to their operation to prepare for the GAPs audit. We asked non-GAPs certified farms about the infrastructure they currently have on their farm. Some of the most common equipment and infrastructure required for GAPs certification include bathrooms and hand-washing stations for workers and visitors, drip irrigation systems, fencing to exclude wildlife, and sinks, tanks, or treatment systems to rinse produce. Depending on the crops cultivated and the risks associated with them or with the farm, farms that lack this equipment may need to invest in it to improve their chances of passing a GAPs audit.

A higher proportion of GAPs certified growers have enclosed areas to pack produce $(65 \%$, vs. $43 \%$ of noncertified growers). Forty-one percent of GAPs certified farmers pack in an open outdoor packing station vs. $48 \%$ of the non-certified growers. This overlap in percentages means that some farmers have both an enclosed and an open packing area. None of the GAPs certified growers reported packing without any protection (i.e., either an open pack shed or an enclosed pack shed) vs. $23 \%$ of the non-certified growers who reported packing without any cover.

Surprisingly, non-GAPs certified farmers are more likely to use a key practice than GAPs certified farmers are. Fourteen percent of the nonGAPs certified growers triple wash their produce and $48 \%$ double wash. In comparison, none of GAPs certified growers triple wash and 12\% double wash their produce. Multiple rinses can decrease the concentrations of pathogens in rinse water and thus reduce the risks of cross-contamination of product. However, we did not ask if growers added disinfectant to their wash water: if the GAPs certified growers use disinfectants in their wash water (as they are required to do), this could explain why they are not triple washing. Another potential explanation to these findings is that GAPs certified growers who grew multiple crops chose to get certified for a single crop that requires minimal washing and processing such as tomatoes, hoophouse raspberries (Rubusidaeus), and hoophouse eggplant (Solanum melongena). 
1. Workers have access to a bathroom and hand-washing facilities 2. Customers have access to hand wash stations 3. Fencing around crop production areas 4. On-farm compost production 5. No irrigation 6. Overhead irrigation

7. Drip irrigation not under plastic 8. Drip irrigation under plastic 9. Spray irrigation and/or fertigation 10. Ground level irrigation: trench/furrow or drip 11. Packing in the field, open to the elements 12. Packing in an open area 13. Packing in an enclosed area 14. No washing or cooling 15. Single wash 16. Double wash

17. Triple wash 18. Store produce in a cooler with thermometer

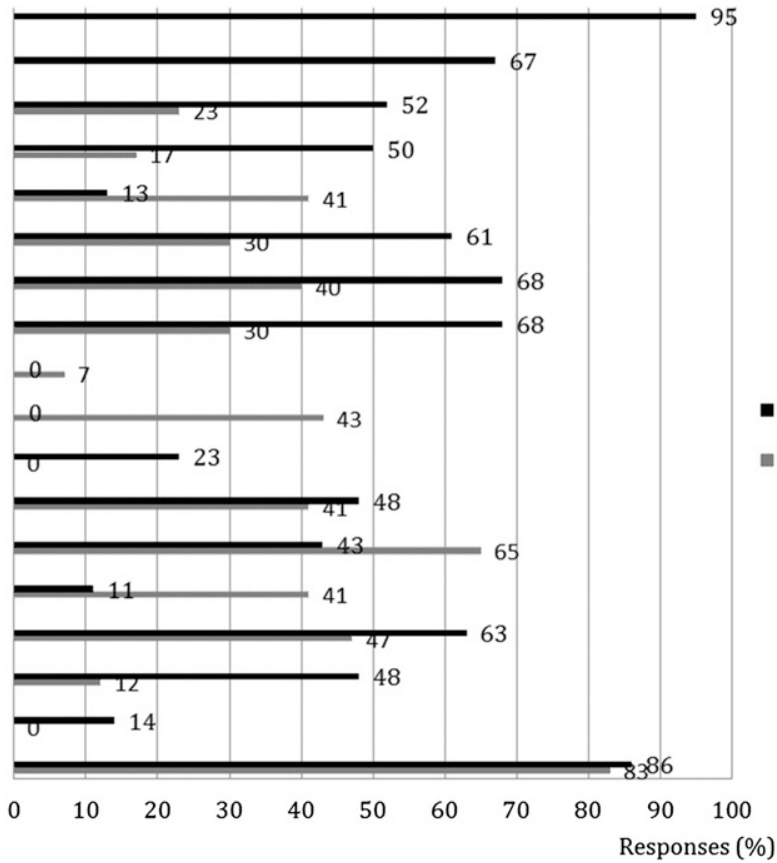

- Non-GAPs Certified ( $\mathrm{n}=62)$ n GAPs Certified $(\mathrm{n}=17)$

Fig. 1. Percentage of farmers who responded "yes" to questions around good agricultural practices (GAPs) related infrastructures on a 2011 online survey of apple and vegetable growers in Vermont. The number to the right of each bars represent the percentage of farmers who responded "yes" to infrastructures or practices listed on the left side of the bars. Responses numbers 1 and 2 are a requirement of the GAPs certification suggesting that all certified farms comply. Responses numbers 7 and 8 were only available to vegetable growers. Responses numbers 9 and 10 were only available to apple growers. The total number of farmers who responded to this question was 79.

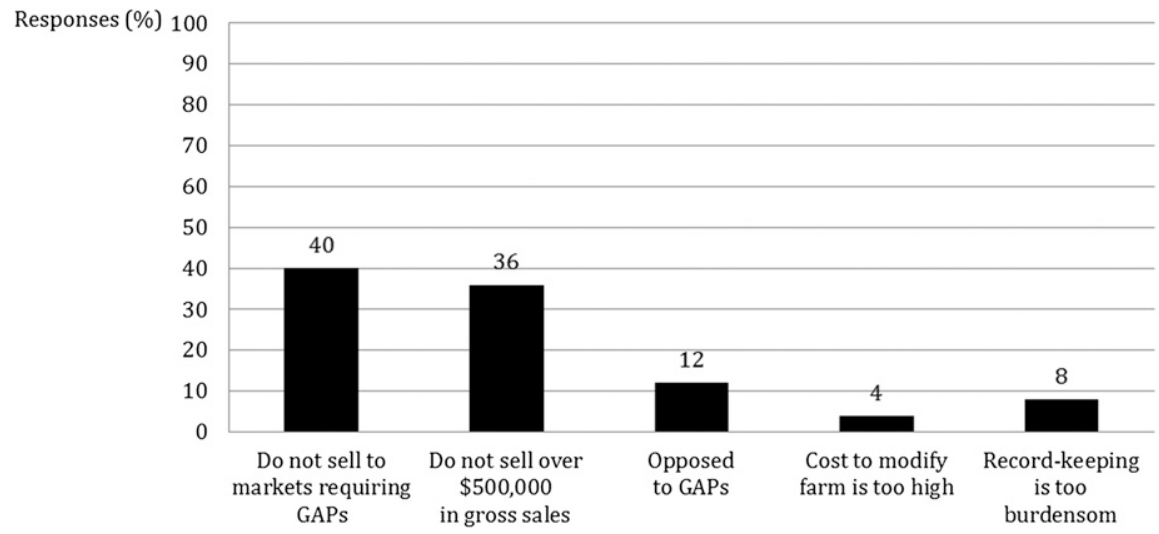

Fig. 2. Percentage of respondents to a 2011 online survey of apple and vegetable growers in Vermont indicating their reason for not seeking good agricultural practices (GAPs) certification. Growers could only choose one of the answers as their main reason for not seeking certification and the number above the bars represent the percentage of growers who choose that answer as their main reason. The total number of farmers who responded to this question was $\mathbf{5 0 .}$

Motivation. The majority $(88 \%)$ of the GAPs certified growers reported getting certified because of a buyer's requirement. Currently in Vermont, two grocery store chains (Price Chopper and Hannaford) and two wholesalers (Red Tomato and J.P. Sullivan) are requiring GAPs certification. The two other reasons reported by growers for seeking this point. Reasons for not seeking GAPs certification included: 1) not selling to markets that require GAPs certification $(40 \%), 2$ ) not selling over $\$ 500,000$ in gross sales - the financial requirement for being exempt from the Food Safety Modernization Act (FSMA) under the Tester Amendment $(36 \%), 3)$ opposition to GAPs (12\%), 4 ) perceived burden of record keeping $(8 \%)$, and 5 ) perceived cost to modify the farm is too high (4\%).

COSTS AND LABOR NEEDS FOR THE GAPs certification. Survey responses revealed a wide range of costs and labor effort needed for GAPs compliance. The expenses of equipment and infrastructure modification ranged between $\$ 50$ and $\$ 24,600$ with a mean of $\$ 3268$ and a median of $\$ 1090$. To get GAPs certified, $65 \%$ of the farms spent money on labels or another aspect of a traceability system, $65 \%$ on bathroom and hand-washing facilities, $41 \%$ on rodent traps, $30 \%$ on fencing and wildlife deterrents, 30\% on their packing area, $24 \%$ on irrigation and potable water systems, and $18 \%$ on washing equipment. Rodent traps constituted one of the smaller expenses at an average expenditure of $\$ 128$ and modifications to packing 
areas constituted one of the larger expenses at an average expenditure of \$2851. The cost of the first audit ranged between $\$ 207$ and $\$ 7000$ with a mean of $\$ 1154$ and a median of $\$ 758$. The cost of the certification including equipment and infrastructure expenses and the audit fees averaged $\$ 3983$. The cost per acre was $\$ 37$ without the cost of the audit fees and $\$ 46$ with the cost of the audit.

GAPs certified farms reported that on average two people were involved in the weekly record keeping, representing about $7 \mathrm{~h}$ per week during the growing season. Examples of GAPs related practices requiring record keeping included keeping a log of the cooler temperatures, and sanitation records for packing sheds and equipment, bathrooms, harvest containers, and trucks.

COMPARISON OF DIFFERENT TYPES OF GAPS CERTIFIED FARMERS. We tested for statistical differences in terms of audit cost, equipment and infrastructure expenses, and labor needs to reach GAPs certification between different types of farmers. Similar to the method used by Hardesty and Kusunose (2009), we compared the means per acre of the different expenditures and labor needs by 1 ) crops grown (vegetables or apples), 2) diversification level (one crop or diversified), 3) farm size measured in sales (less than $\$ 500,000$ in sales or more than $\$ 500,000$ in sales), and 4) marketing channels focusing on sales made to supermarkets (less than 50\% sold to supermarkets or more than $50 \%$ sold to supermarkets). We compared the means per acre of the different variables with the non-parametric Mann-Whitney $U$ test (Table 2). Significant statistical differences include: 1) cost of the audit for the group crops grown $(P \leq 0.05), 2)$ workers involved in record keeping for the group level of sales $(P \leq 0.05)$, and 3 ) time spent on record keeping for groups crops grown and marketing channels $(P \leq 0.05)$. We found no statistical significance for any other variables and groups.

These results suggest that mean costs per acre are not statistically different except for the variables mentioned above. The cost of the audit was higher for vegetable growers than it was for apple growers. The time spent recordkeeping was higher on apple orchards than it was on

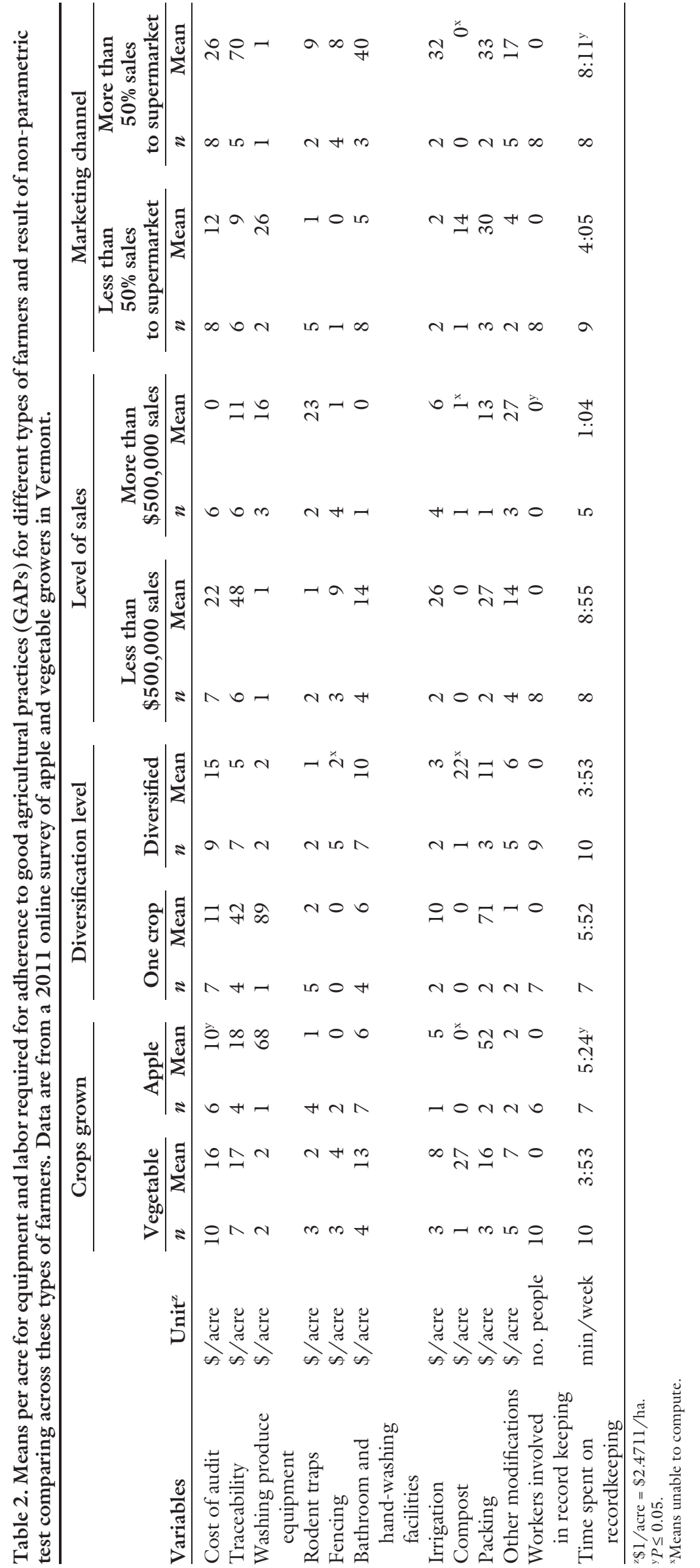

Hortlechnology • October 2012 22(5) 
vegetable farms, it was also higher for farmers that sell more than $50 \%$ of their production to supermarkets. Looking at farm size measured by annual sales greater vs. less than $\$ 500,000$, there does not appear to be an economy of scale except for number of workers involved in record keeping. The absence of economies of scale may be explained by the small sample size and similarity of scale across the sample.

\section{In-depth interview results}

The 10 farms participating in indepth interviews represent $50 \%$ of the farms that went through the USDA GAPs audit in the state of Vermont in 2010 (the year before which the study was conducted) and the average acreage of these farms was 57 acres. Of these 10 farms, all completed the general questions, the farm review (Part 1) and field harvest and field packing sections (Part 2) of the USDA GAPs audit. Three of the 10 farms also completed house packing (Part 3) and storage and transportation (Part 4 ). None of the farmers interviewed were audited for the wholesale distribution center and terminal warehouse (Part 6) or preventive food defense (Part 7) sections. Nine out of 10 farmers reported going through the GAPs certification to keep an account with local supermarket chains like
Hannaford or Price Chopper. The remaining farmer reported going through the certification because of expansion plans and wanting the ability to sell to markets that might require it.

Costs OF EQUIPMENT AND INFrASTRUCTURE. Since not all the farmers went through all of the sections of the audit, we analyzed the data for each section of the audit separately (Table 3). As mentioned above, the main supermarkets requiring GAPs certification in Vermont only required adherence to the first three sections of the audit for at least one crop. For the general section, the cost of equipment purchases and infrastructure modifications ranged from $\$ 297$ to $\$ 8800$ with a mean of $\$ 2468$ and a median of $\$ 1659$. For farm review (Part 1), the cost of the infrastructure modification and supply purchases ranged from $\$ 18$ to $\$ 764$ with a mean of $\$ 174$ and a median of $\$ 119$. For field harvest and field packing activities (Part 2), the cost of the infrastructure modification and supply purchases ranged from $\$ 209$ to $\$ 1273$ with a mean of $\$ 704$ and a median of $\$ 630$. For house packing (Part 3 ), the cost of the infrastructure modification and supply purchases ranged from $\$ 50$ to $\$ 1447$ with a mean of $\$ 720$ and a median of $\$ 665$. Only one farm incurred expenses for storage and transportation
(Part 4) for which the cost of equipment purchases and infrastructure modifications was \$410. Overall, the total cost ranged between $\$ 297$ and $\$ 10,574$ with a mean of $\$ 3076$ and a median of $\$ 2237$. Average cost per acre was $\$ 54$. Common expenses included mobile hand-washing stations, mobile toilets, first aid kits, water tests, flash tape, scare balloons, rodent traps, washable harvest containers, signage, notebooks, and thermometers for walk-in coolers. Fees associated with the audit itself ranged from $\$ 207$ to $\$ 947$ with a mean of $\$ 638$ and median of $\$ 727$. The differences in the audit costs stem from farmers' paying for the auditor's time (charged at $\$ 92 / \mathrm{h}$ including one way travel), that some farms were being audited for more than one crop, and that some farms were being audited for more than the first three sections of the audit. Additional crops or additional sections resulted in more time spent on the farm by the auditor and thus higher costs associated with certification. When we removed the cost of the audit from the other costs, we found that the cost of GAPs certification without the audit was $\$ 46 /$ acre.

LABOR NEEDs. As part of the indepth interviews, farmers estimated the time spent doing GAPs related tasks. Labor associated with GAPs

Table 3. Costs of good agricultural practices (GAPs) certification for the different sections of the audit based on 10 in-depth interviews of vegetable and apple growers in Vermont in 2011.

\begin{tabular}{|c|c|c|c|c|c|c|}
\hline & Total cost for first yr certification & $n^{\mathrm{z}}$ & Mean & Median & Minimum & Maximum \\
\hline General questions & $\$ 24,677$ & 10 & $\$ 2,468$ & $\$ 1,659$ & $\$ 297$ & $\$ 8,800$ \\
\hline Part 1 -Farm review & $\$ 1,399$ & 8 & $\$ 174$ & $\$ 119$ & $\$ 18$ & $\$ 764$ \\
\hline Part 3-House packing facility & $\$ 2,162$ & 3 & $\$ 720$ & $\$ 665$ & $\$ 50$ & $\$ 1,447$ \\
\hline Part 4-Storage and transportation & $\$ 410$ & 1 & $\$ 410$ & $\$ 410$ & $\$ 410$ & $\$ 410$ \\
\hline
\end{tabular}

${ }^{\text {zAlthough }} 10$ farms were interviewed, the $n$ varies as all not all of the interviewees were certified for all of the sections.

Table 4. Labor required for good agricultural practices (GAPs) certification for each sections of the audit based on 10 indepth interviews of vegetable and apple growers in Vermont in 2011.

\begin{tabular}{|c|c|c|c|c|c|c|}
\hline & Labor for first yr certification (h) & $n^{\mathrm{z}}$ & Mean & Median & Minimum & Maximum \\
\hline Part 1 -Farm review & 632 & 9 & 70 & 38 & 7 & 192 \\
\hline Part 3-House packing facility & 414 & 3 & 138 & 128 & 94 & 192 \\
\hline Part 4-Storage and transportation & 161 & 2 & 80 & 80 & 39 & 122 \\
\hline
\end{tabular}

${ }^{\mathrm{z}}$ Although 10 farms were interviewed, the $n$ varies as all not all of the interviewees were certified for all of the sections. 
certification took farmers and their employees between 17 and $827 \mathrm{~h}$ with a mean of $322 \mathrm{~h}$ and a median of $306 \mathrm{~h}$ (Table 4). On average, they spent the most time on the general questions $(161 \mathrm{~h})$ and on the house packing facility $(138 \mathrm{~h})$. Some of these tasks only occur once per year such as writing a food safety plan or conducting a mock recall, while some of the tasks take place on a weekly or daily basis such as keeping the logs up to date, cleaning the bathroom, and cleaning the packing containers. There were between one and six people on farms involved in record keeping and they spent an average of $3 \mathrm{~h} /$ week during the growing season keeping the records up to date.

COMPARISON OF THE SURVEY AND IN-DEPTH INTERVIEW RESULTS. Sample size was 17 for the survey and 10 for the in-depth interviews. Based on the survey results, the first audit cost GAPs certified farms on average \$1154 (ranging from \$207 to \$7000), while the average cost we found from the indepth interviews was $\$ 638$ (ranging from $\$ 207$ and \$947). In terms of investments in equipment or infrastructure modifications, the average expense from survey respondents was $\$ 3268$ (ranging from $\$ 50$ to $\$ 24,600$ ). In comparison, we found through the in-depth interviews that the average cost was \$3076 (ranging from \$297 to $\$ 10,574)$. We used the MannWhitney $U$ test to test the null hypothesis that the average cost of the first audit and the investments in equipment and infrastructure modifications do not vary between the survey results and the in-depth interviews. We failed to reject the null hypothesis $(P \leq 0.1)$ indicating that the average costs of audit and modification are not significantly different between samples.

ExTRAPOLATIONS OF THE RESULTS. Using data from our research and from the USDA Agriculture Census (USDA, 2007c, 2007d), we calculated what it would cost to get all the vegetable and apple growers in Vermont GAPs certified. Estimating the cost of certifying all farms in Vermont is relevant for several reasons even though the extrapolation of the results is exploratory and limited. First, the Vermont Agency of Agriculture (Montpelier, VT) offered a cost share program in 2011 to help farmers make capital improvements associated with the certification process and improving infrastructure associated with produce safety practices (Loftus, 2011). The estimated cost of certifying all Vermont farms can help to inform appropriate allocation of funds and help state policymakers plan better in light of the FSMA.

According to the U.S. Census of Agriculture, in 2007, there were 758 produce farms in Vermont (494 vegetable farms and 264 apple orchards) representing 6168 cultivated acres (USDA, 2007c, 2007d). The highest estimate of the cost per acre of the GAPs certification we found was $\$ 54$ (result from the in-depth-interviews including cost of infrastructure and equipment and cost of the audit). Multiplying 6168 acres by $\$ 54 /$ acre equals an estimated $\$ 333,072$ to certify all farms. The lowest estimate of the cost per acre we found was $\$ 37$ (result from the survey including only the cost of the infrastructure and equipment). Certifying all the commercial produce farms in Vermont would in that case cost a minimum of $\$ 228,216$. Multiplying the average cost per farm by the total number of farms increases the estimated cost to certify all the farms in Vermont. The average cost estimate per farm ranged between $\$ 2599$ (result from the in-depth interviews including only the cost of infrastructure and equipment) and $\$ 3983$ (result from the survey including cost of infrastructure and equipment and cost of the audit). Using these figures, certifying the 758 produce farms would cost between $\$ 1,970,042$ and $\$ 3,019,114$.

\section{Discussion}

The goal of our research study was to answer three research questions: 1) how much does GAPs certification cost farmers, 2) how much additional labor is required for GAPs certification, and 3 ) how much it would cost to certify all farms in Vermont. In the discussion, we compare our findings to those of previous studies and talk about our contribution to the current literature. A comparison of the results from our study with those of Hardesty and Kusunose (2009), Woods and Thornsbury (2005), and Estrin (2010) explores economies of scale in food safety certification; specifically, the larger the farm, the more units over which the cost of certification is spread out. Hardesty and Kusunose found that farmers with a revenue higher than $\$ 10$ million benefited from economies of scale and better capacity to absorb the cost of compliance. Similarly, Woods and Thornsbury concluded that because many of the costs associated with GAPs adoption do not vary with farm size or the amount of strawberries produced that therefore smaller growers incur higher costs than larger growers. In our study, we found no economy of scale for equipment purchased but we did find an economy of scale for the number of people involved in recordkeeping. These findings can be explained by our small sample size and farm homogeneity. It is important to note that it is difficult to make direct comparisons between these studies since Hardesty and Kusunose were exploring the cost of the LGMA, Woods and Thornsbury only focused on five criteria of the GAPs certification, and Estrin estimated the cost for compliance with all sections of the audit but the farmer in that study only went through three sections of the audit. Yet it is still worthwhile to contrast the studies to determine if the calculations and estimations are in close range or if they differ a great deal. The range of costs per acre between the four studies varies from $\$ 46$ to $\$ 288$ with a mean of $\$ 95$ and a median of $\$ 60$ (Table 5 ).

Our study contributes to the current literature by measuring the costs of GAPs compliance on a diverse sample of farms. We found that statistically significant differences between GAPs certified farms and nonGAPs certified farms terms of acreage, number of workers, and sales directly to consumers, supermarkets, and wholesale markets. We found that GAPs certified farms tend to be bigger than non-certified farms and they tend to sell a higher proportion of their production to supermarkets, while non-GAPs certified farms sell a high proportion of their production directly to consumers. Indeed, $88 \%$ of the GAPs certified farmers reported seeking certification because of a buyer requirement, mostly supermarkets. When testing for statistical significance between different groups of GAPs certified growers, we found the cost of the audit to be higher for vegetable growers than for apple growers while time spent on recordkeeping was higher on apple orchards. 


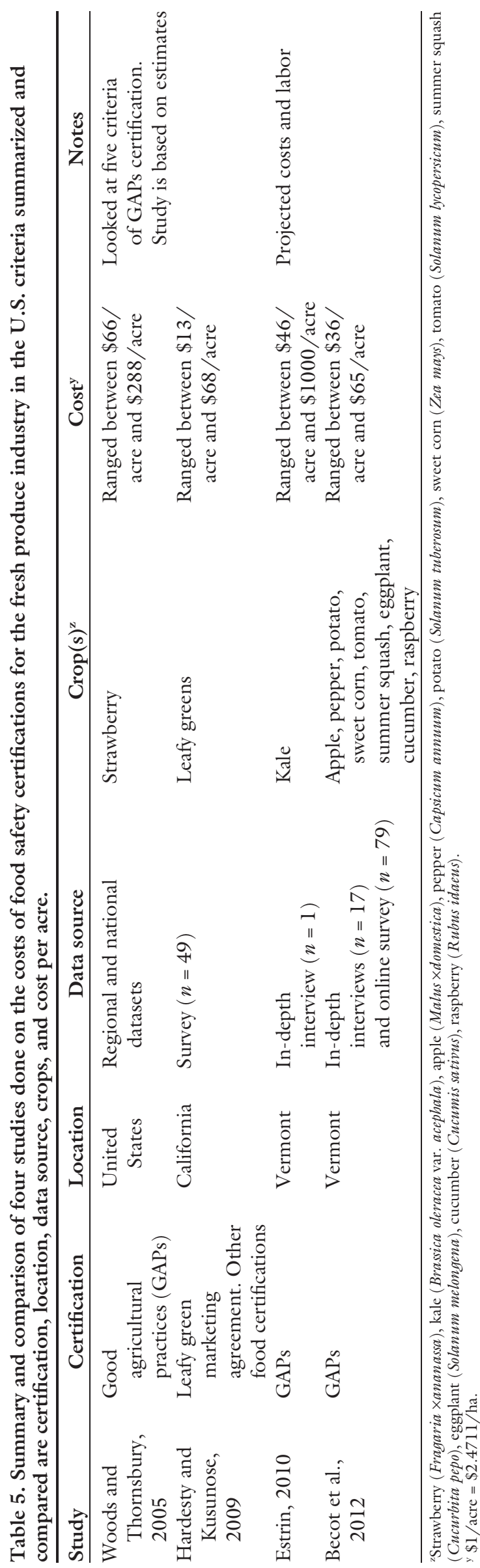

We found no statistical differences for equipment and infrastructure spending between farmers who grow one crop vs. diversified farmers, farmers who sell less than $\$ 500,000$ annually vs. farmers who sell more, and farmers who sell less than $50 \%$ of their production to supermarkets vs. farmers who sell more.

We estimated that it would cost between $\$ 228,216$ and $\$ 3,019,114$ to certify all the farms in Vermont depending on the method of calculation used. These figures are preliminary and are limited, actual costs to certify all commercial produce operations in Vermont might be considerably higher as only three of the farmers interviewed were audited for their packing area, and infrastructure and equipment costs related to packhouses, storage, and transportation will most likely be the largest source of food safety related expenses for Vermont's produce industry (V. Nickerson, unpublished data). Had more farmers gone through that section, the average cost of certification may have been higher. Also, as noted in the study by Estrin (2010), certification costs can vary depending on level of compliance with the audit checklist and whether farmers choose to purchase new equipment or repair existing equipment.

The major limitations of our study are a non-representative sample and relatively low response rate. Nevertheless, our research begins to measure the cost of GAPs on diversified farms in terms of infrastructure, equipment, audits, and labor, using primary data. Although all farms should follow good hygiene and sanitation practices, using this information, extension educators and other agricultural service providers can help farmers decide whether GAPs certification is appropriate for them based on the markets channels to which they wish to sell and the potential costs of certification to their operation.

\section{Conclusion}

Our study identified the most common expenses and labor required for reaching GAPs certification. Future research could study a larger number of farmers as they go through the certification process, reducing the chances for inaccurate recollection or lapses in the recordings of expenses. It also would be valuable to study produce buyers purchasing needs and 
requirements to determine if farmers are preparing appropriately for the type of food safety assurances that will be required by their markets. Collaboration across disciplines is important. Food safety standards need to be scientifically based but also scale appropriate and economically feasible in order for produce growers to adopt them efficiently and adequately.

\section{Literature cited}

Almanza, B. and M. Nesmith. 2004. Food safety certification regulations in the United States. J. Environ. Health 66: 10-14.

Bassett, J. and P. Mcclure. 2008. A risk assessment approach for fresh fruits. J. Appl. Microbiol. 104:925-943.

Bihn, E. and R. Gravani. 2006. Role of good agricultural practices in fruit and vegetable supply, p. 21-53. In: K. Matthews (ed.). Microbiology of fresh produce. ASM Press, Washington, DC.

Calvin, L. 2003. Produce, food safety, and international trade: Response to U.S. foodborne illness outbreaks associated with imported produce. U.S. Dept. Agr., Washington, DC.

Calvin, L., B. Avendaño, and R. Schwentesius. 2004. The economics of food safety: The case of green onions and hepatitis $A$ outbreak. U.S. Dept. Agr., Washington, DC.

Centers for Disease Control and Prevention. 2011. CDC 2011 estimates: Findings. 12 Sept. 2011. <http://www.cdc.gov/ foodborneburden/2011-foodborneestimates.html\#annual>.

De Roever, C. 1998. Microbiological safety evaluations and recommendations on fresh produce. Food Control 9:321347.

Estrin, H. 2010. Here comes GAP certification! The inside story of a Vermont farmer going for USDA GAP certification. Univ. Vermont, Brattleboro, VT.

Giard, V. 2003. Statistique appliquee a la gestion. Economica, Paris.

Hardesty, S. and Y. Kusunose. 2009. Growers' compliance costs for the leafy greens marketing agreement and other food safety program. Univ. California
Small Farm Res. Brief, Sept. 2009. Univ. California, Davis, CA.

Hultberg, A., M. Schermann, and C. Tong. 2012. Results from a mail survey to assess Minnesota vegetable growers' adherence to good agricultural practices. HortTechnology 22:83-88.

Hunter, J., K. Johnson, J. Young Marks, L. Pascal, and C. Thomas. 2010. An analysis of food safety in Wisconsin. 30 July 2011. <http://www.lafollette.wisc. edu/publications/workshops/2010/ foodsafety.pdf>.

Loftus, K. 2011. Agency of agriculture, food and markets launches good agricultural practices (GAPs) capital improvement grant program. 30 Sept. 2011. <http://www.vermontagriculture.com/ news/2011/GAPJuly21.html>.

Mead, P., L. Slutsker, V. Dietz, L. Mccaig, J. Bresee, C. Shapiro, P. Griffin, and R. Tauxe. 1999. Food-related illness and death in the United States. Emerg. Infect. Dis. 5:607-625.

Norusis, M. 2006. SPSS 15.0 guide to data analysis. Prentice Hall, Upper Saddle River, NJ.

Paggi, M. 2008. An assessment of food safety policies and programs for fruits and vegetables: Food-borne illness prevention and food security. 30 July 2011. <http:// naamic.tamu.edu/austin/paggi.pdf $>$.

Rejesus, R. 2009. GAP certification: Is it worth it? 30 July 2011. <http://www4. ncsu.edu/ rmrejesu/Food_Safety_Risk/ ag-709\%20final\%20printed.pdf>.

Smith Dewaal, C., C. Roberts, and C. Catella. 2012. Outbreak alert! 1999-2008. 23 Mar. 2012. <http://www.cspinet.org/ foodsafety/PDFs/Outbreak_Alert_1999. 2008.pdf>.

Tobin, D., J. Thomson, L. Laborde, and J. Bagdonis. 2011. Developing GAP training for growers: Perspectives from Pennsylvania supermarkets. J. Ext. 49(5). 23 Mar. 2012. <http://www.joe.org/ joe/201loctober/rb7.php>.

U.S. Department of Health and Human Services. 2010a. 2020 Topics and objectives: Food safety. 23 Mar. 2012. <http:// www.healthypeople.gov/2020/topics objectives2020/overview.aspx?topicid $=14>$.

U.S. Department of Health and Human Services. 2010b. 2020 Topics and objectives: Nutrition and weight status. 23 Mar. 2012. <http://www.healthypeople. gov/2020/topicsobjectives $2020 /$ over view .aspx? topicid $=29>$.

U.S. Department of Health and Human Services, Food and Drug Administration, and Center for Food Safety and Applied Nutrition. 1998. Guide to minimize microbial food safety hazards for fresh fruits and vegetables. 30 July 2011. <http:// www.fda.gov/downloads/Food/Guidan ceComplianceRegulatoryInformation/ GuidanceDocuments/ProduceandPlan Products/UCM169112.pdf>.

U.S. Department of Agriculture. 2007a. Good agricultural practices and good handling practices audit verification checklist. 30 July 2011. <http://www.ams.usda. gov/AMSv1.0/GAPGHPAuditVerific ationProgram\#P51_2571>.

U.S. Department of Agriculture. 2007b. Table 46, Selected characteristics of farms by north american industry classification system: 2007. 10 Sept. 2011. <http://www. agcensus.usda.gov/Publications/2007/ Full_Report/Volume_1,_Chapter_1_US/ st99_1_046_046.pdf>.

U.S. Department of Agriculture. 2007c. Table 35, Specified fruits and nuts by acres: 2007 and 2002. Vermont. 10 Sept. 2011. <http://www.agcensus.usda. gov/Publications/2007/Full_Report/ Volume_1,_Chapter_1_State_Level/ Vermont/st50_1_035_036.pdf>.

U.S. Department of Agriculture. 2007d. Table 34, Vegetables, potatoes, and melons harvested for sale: 2007 and 2002. Vermont. 10 Sept. 2011. <http:// www.agcensus.usda.gov/Publications/ 2007 /Full_Report/Volume_1,_Chapter_ 1_State_Level/Vermont/st50_1_034_ 034.pdf>.

U.S. Department of Agriculture. 2011. Fruits and vegetables (fresh weight equivalent): Per capita availability, 1970-2009. 10 Sept. 2011. <http://webcache.google usercontent.com/search?q=cache:3Utx of7A19cJ:www.ers.usda.gov/datafiles/ Food_Availabily_Per_Capita_Data_System/ Food_Availability/fruitveg.xls $+\& \mathrm{~cd}=1 \& \mathrm{hl}=$ en\&ct $=\mathrm{clnk} \& \mathrm{gl}=\mathrm{us}>$.

Vermont Sustainable Jobs Fund. 2011. Farm to plate initiative strategic plan. Vermont Sustainable Jobs Fund, Montpelier, VT.

Woods, M. and S. Thornsbury. 2005. Costs of adopting good agricultural practices (GAPs) to ensure food safety in fresh strawberries. Michigan State Univ., Agr. Econ. Rpt. 624. 